\title{
Business Process Reengineering Implementation: Developing a Causal Model of Critical Success Factors
}

\author{
Gholamreza Jamali, Mohammad Ali Abbaszadeh, Mehran Ebrahimi, and Tahereh Maleki
}

\begin{abstract}
Business Process Reengineering (BPR) has become a popular managerial tool to deal with dramatic technological and business changes in today's competitive environment. BPR help organizations to throw away their old fashioned processes to achieve new heights of success. However, BPR implementation is a difficult task. Literature indicates that many organizations have failed to achieve the expected results. The present study attempts to throw more light to the subject. Through a comprehensive review of literature, critical success factors (CSF) that influence the success of BPR programs are identified. Then, using a DEMATEL methodology, these CSF and the causal relationships among them are analyzed. Results indicate that "top management commitment", "IT infrastructure", "training" and "adequate financial resources" are of critical importance in BPR implementation projects.
\end{abstract}

Index Terms-Business process reengineering, critical success factor, implementation.

\section{INTRODUCTION}

The dramatic changes in business environment have drastically enforced enterprises to increase organizational awareness and responsiveness in internal and external environments. According to Hesson et al. [1], the efficiency of administrative processes has become a major concern for many organizations. Consequently, traditional management tools and techniques can no longer help enterprises in new circumstances. Organizations must focus on the development of more flexible, coordinative, team- and communication-based capabilities [2]-[4].

Since the 1990s, organizations have paid special attention to "processes" [5], [6]. In the search to improve and speed up the organizational processes, different tools and techniques have been developed in two last decades [7]. One of these tools is business process reengineering which has gained widespread attention from both academics and industry. BRP is a popular management approach, which enables organizations to handle with rapid business and technological changes. Business Process Reengineering (BPR) can radically transform organizations for dramatic improvement [8].

BPR introduced as the savior of under-performing organizations in the early 1990s by Hammer [9], [10] and

Manuscript received December 10, 2011; revised December 16, 2011.

G. Jamali is with Persian Gulf University of Bushehr, Bushehr, Iran (email: gjamali@pgu.ac.ir).

M. A. Abbaszadeh is with Tehran University, Kish International Campus, Kish, Iran (email: ma.abaszadeh@yahoo.com).

M. Ebrahimi is with Persian Gulf University, Bushehr, Iran(email: imjebrahimi@yahoo.com).

T. Maleki is with Islamic Azad University, Center Tehran Branch (email: maleki1359_azad@yahoo.com).
Davenport and Short [11] followed by Hammer and Champy [12], Davenport [13], [14] and Champy [15]. Since its initiation BPR has become a popular management tool for dealing with technological and business changes in the competitive environment [16]. Early advocates of BPR touted it as the next revolution in obtaining breakthrough performance via process improvement and process change [17]. Since 1990, different researchers such as Hammer [9], Harrington [18], Klein [19], Davenport [13], Johansson et al. [20], and Dixon et al. [21] have developed different definitions of BRP. Hammer and Champy [12] defined BPR as a fundamental redesign of organizational processes to create radical improvement in vital areas such as cost, quality, service, and speed. In another attempt, Manganelli and Klein [22] defined BPR as a structured approach, which continuously improves critical activities of organization such as marketing, production and communication.

Four common keywords in BPR definitions are "fundamental", "radical", "dramatic" and "process". BPR determines what a company must do and the how to do it .To improve productivity and quality, a business process has to undergo fundamental changes [23], [24]. Radical changes (not superficial changes) are made to create dramatic improvements. Through radical changes old fashioned processes threw away. The word dramatic concern with achieving quantum leaps in performance. Process refers to a collection of activities which gets a set of input and creates a set of outputs that is of value to customer [23], [25], [26].

The essence of BPR is to make a systematical enterprise revolution. The primary goal is to redesign and restructure those key work processes which face the customers directly and provide customers with value [27]. BPR focuses on the whole process. With the help of Information Technology (IT), BPR provides the opportunity to reengineer the process, reduce radically the number of activities to carry out a process and find new ways of to do things [9], [12]. BPR helps organizations to change their old fashioned structures into cost efficient, effective [28] and innovative processes [13].

BPR has been implemented in both service [29]-[30][31] and manufacturing firms [32] in different countries around the world. Successful implementation of BPR brings many benefits to the organization. According to Farmer [33] customer satisfaction, increased productivity, higher flexibility, increased employees and improved coordination, and improved competitive advantage are the main benefits of successful BPR implementation. BPR helps organizations to achieve new heights of success by dramatically changing existing business processes [33]-[36].

Despite the numerous advantages of BPR, its implementation is perceived to be a difficult task and many 
unsuccessful experiences have been reported in the literature. $\mathrm{BPR}$ is a risky operation. According to Al-Mashari et al. [2], Hall et al. [29], Dennis et al. [37], Holland and Kumar [38] and Chiplunkar et al. [39] 50-70 percent of BPR efforts fail to achieve its programmed results. Accordingly, to implement BPR successfully, critical success factors should be identified and analyzed [40]. In terms of BRP, critical success factors (CSFs) are areas which organization must accomplish to achieve a successful implementation.

Small and medium sized enterprises (SMEs) are of critical importance to the development and prosper of many economies. Nowadays, an increasing number of SMEs tend to involve in BPR initiatives. Successful BPR implementation enables SMEs to achieve dramatic gains in business performance. However, a comprehensive review of literature indicates that much has been written about BPR implementation in large organizations, and little attention has been paid to the SMEs. In an attempt to help managers and practitioners to implement BRP projects successfully, the present paper tries to identify and analyze the CSFs in the Iranian SMEs context. Thus, the main objectives of this paper are:

- to identify CSFs for BPR implementation in Iranian SMEs;

- $\quad$ to find out the relationships between CSFs;

- to developed a causal model of CSFs in BPR implementation;

- to categorize the identified CSFs into driver and dependent groups;

- to contribute to the development of BRP theory by investigation of the causal relationships between the identified CSFs; and

- to provide insights for managers aimed at BRP implementation.

The reminder of this paper is organized as follows. The next section discusses and explains the CSFs for BPR implementation. The DEMATEL method along with practical solving procedure is presented in section 3. Finally, the finding of this research are presented, which is followed by discussion and conclusion.

\section{CRITICAL SUCCESS FACTORS FOR BPR IMPLEMENTATION}

Successful implementation of BRP involves defining and deployment of several critical success factors. To date, different researchers have defined different CSFs for successful BRP implementation. Based on a comprehensive review of the literature, viewpoints of the academics and interviews with several SME managers, 7 BRP CSFs have been identified. These CSFs are presented in TABLE I. Some supportive studies and a brief explanation of these CSFs are also presented in this section.

\section{A. Collaborative Working Environment}

Collaborative working environment is one of the most widely cited factors in the literature. In organizations, employees work together. Having friendly interactions is a main feature of any dynamic environment. Collaborative climate reduces resistance to change and simplifies BPR implementation [1], [2], [35]. Previous research indicate that to be successful, BPR should focus on achieving the empowerment of people and the application of appropriate enabling technology [50].

TABLE I: CSFS FOR BRP IMPLEMENTATION

\begin{tabular}{|c|c|c|}
\hline No & Factor & Author \\
\hline 1 & Collaborative working environment & $\begin{array}{c}\text { [4], [5], [8], [36], [37], [41], } \\
{[42],[43],[44],[45] .}\end{array}$ \\
\hline 2 & $\begin{array}{c}\text { Top management commitment and } \\
\text { Support }\end{array}$ & $\begin{array}{c}{[4],[5],[8],[36],[37],[41],} \\
{[42],[43],[44],[45],[46],} \\
{[47] .}\end{array}$ \\
\hline 3 & IT infrastructure & $\begin{array}{c}{[5],[8],[36],[37],[41],[42],} \\
{[43],[44],[48],[49] .}\end{array}$ \\
\hline 4 & Training & {$[4],[8],[37],[41],[45],[47]$} \\
\hline 5 & Less bureaucratic structure & [4], [8], [46], [47]. \\
\hline 6 & Culture & $\begin{array}{c}4],[5],[8],[37],[41],[42], \\
{[44],[45],[46],[47] .} \\
\end{array}$ \\
\hline 7 & Adequate financial resources & {$[4],[8],[46]$.} \\
\hline
\end{tabular}

\section{B. Top Management Commitment and Support}

Top management plays the most important role in the organization and determines the strategic direction of the organization [2], [29], [39]. The degree of top management support in BPR implementation is very critical. Top management should have adequate knowledge about BPR implementation and make important decisions in BPR implementation process. In addition top management should motivate employees and have a friendly interaction with BPR team [5], [37], [42]. The role of top management in creation of an organization climate that empowers employees is of crucial importance.

\section{IT Infrastructure}

To achieve the expected results in BPR implementation, appropriate IT infrastructure is needed. In most projects, BPR starts from IT department. IT is a natural partner of BPR and plays a critical and central role in BPR projects [8], [41]. IT not only speeds up the process to be carried out but also integrate processes and reduces errors, hence improves productivity [44], [49].

\section{Training}

Training plays a crucial role in BPR implementation. Since BPR changes the organizational processes, employees should have adequate skills to do the new tasks. Through a proper training program, employees will have an in-depth comprehending of their new tasks [4], [45], [47].

\section{E. Less Bureaucratic Structure (Flatter Structure)}

A flexible organizational structure enables BPR to encourage creativity and innovativeness in the organization. Therefore having a less bureaucratic and more participative structure is essential for successful BPR implementation. This is parallel with McAdam [51] statement that organizations should apply a more participative structure to avoid failure of BPR implementation [46].

\section{F. Culture}

Culture has been recognized as a CSF for BPR implementation in the literature [5], [8], [37], [41], [42], [44]. Coordination, employees' involvement and friendly interactions are the standard feature of an innovative organizational culture. Effective utilization of employees' ideas enables organizations to achieve their expected results. 
Further, a strong appropriate culture makes positive changes, avoids stress and reduces resistance to change.

\section{G. Adequate Financial Resources}

Obviously, implementing BPR without adequate financial resources is unthinkable. Budget allocation to BPR is a long-term investment for achieving favorable results. BPR implementation is a costly process. Therefore, organizations should have adequate financial resources for implementing changes and facing with unpredictable situations [4], [8], [46].

\section{MeTHODOLOGY}

To comprehend the causal relationships between the elements of a complex system, a systematic and logical approach is needed [52]. DEMATEL, a comprehensive method developed by the Science and Human Affairs Program of the Battelle Memorial Institute of Geneva is a tool that meets the objective of understanding the causal relationships among elements [53]. DEMATEL allows researchers and managers to gain a deeper understanding of the relationships among variables. It has been successfully applied in different fields. TABLE II illustrates some of its applications.

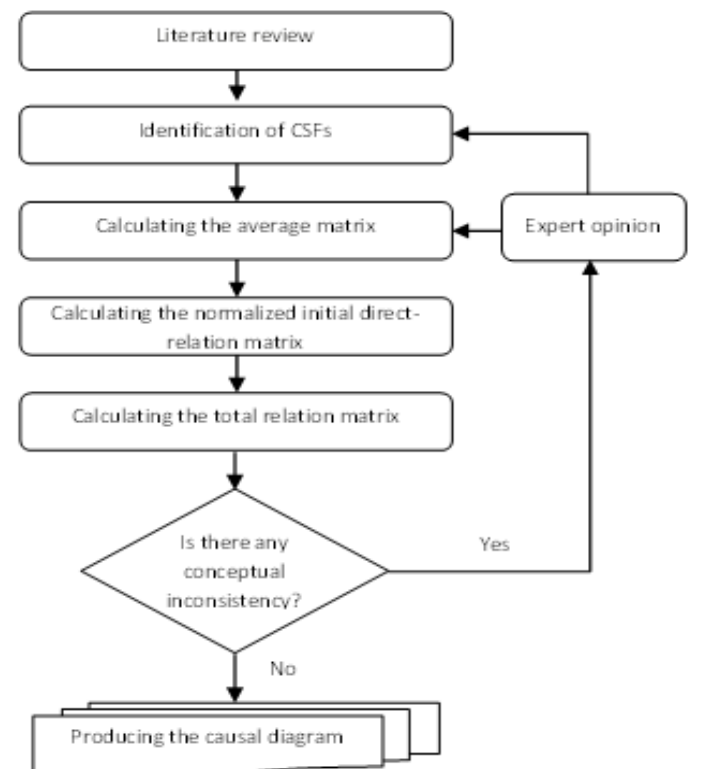

Fig. 1. Flow diagram for preparing the causal diagram.

\section{A. Calculate the Average Matrix}

In the first step, respondents are asked to evaluate the direct influence between any two factors by an integer scale from $0,1,2$, and 3, representing "no influence", "low influence", "medium influence", and "high influence", respectively.

To develop the causal model, 17 experts, including Iranian SMEs managers and academia were consulted. Each respondent would produce a direct matrix, and an average matrix $A$ is then derived through the mean of the same factors in the various direct matrices of the respondents. The average matrix $A$ is shown in TABLE III.
TABLE II: APPLICATION OF DEMATEL

\begin{tabular}{|c|c|c|}
\hline Sr. No. & Authors & Area in which DEMATEL has been applied \\
\hline 1 & $\begin{array}{c}\text { Abbaszadeh et al. } \\
{[52]}\end{array}$ & Knowledge management implementation \\
\hline 2 & Shieh et al. [53] & Hospital service quality \\
\hline 3 & Jamali et al. [54] & TQM implementation \\
\hline 4 & Ho et al. [55] & Portfolio selection \\
\hline 5 & Tsai and Chou [56] & management systems selection \\
\hline 6 & Wu [57] & Knowledge management strategy selection \\
\hline
\end{tabular}

TABLE III: THE AVERAGE MATRIX

\begin{tabular}{|c|c|c|c|c|c|c|c|}
\hline Factor & $\mathrm{F}_{1}$ & $\mathrm{~F}_{2}$ & $\mathrm{~F}_{3}$ & $\mathrm{~F}_{4}$ & $\mathrm{~F}_{5}$ & $\mathrm{~F}_{6}$ & $\mathrm{~F}_{7}$ \\
\hline $\mathrm{F}_{1}$ & 0.000 & 0.000 & 0.000 & 0.000 & 2.454 & 0.000 & 0.000 \\
\hline $\mathrm{F}_{2}$ & 1.987 & 0.000 & 0.000 & 2.564 & 1.763 & 2.654 & 2.365 \\
\hline $\mathrm{F}_{3}$ & 1.872 & 0.000 & 0.000 & 1.524 & 1.972 & 2.625 & 0.000 \\
\hline $\mathrm{F}_{4}$ & 1.524 & 0.000 & 0.000 & 0.000 & 1.625 & 2.524 & 0.000 \\
\hline $\mathrm{F}_{5}$ & 2.413 & 0.000 & 0.000 & 0.000 & 0.000 & 0.000 & 0.000 \\
\hline $\mathrm{F}_{6}$ & 2.431 & 0.000 & 0.000 & 0.000 & 2.762 & 0.000 & 0.000 \\
\hline $\mathrm{F}_{7}$ & 0.000 & 0.000 & 2.524 & 2.442 & 1.652 & 0.000 & 0.000 \\
\hline
\end{tabular}

\section{B. Calculate the Normalized Initial Direct-Relation Matrix}

Based on the average matrix $A$, the normalized direct-relation matrix $M$ can be obtained through the equations (1) and (2). The normalized initial direct-relation matrix is illustrated in TABLE IV.

$$
\begin{gathered}
M=k \cdot A \\
k=\frac{1}{\max _{1 \leq i \leq n} \sum_{j=1}^{n} a_{i j}} \quad, i, j=1,2, \ldots, n
\end{gathered}
$$

where, the notation of $a_{i j}$ indicates the degree to which factor $\mathrm{i}$ affects on factor $\mathrm{j}$ in average.

TABLE IV: THE NORMALIZED INITIAL DIRECT-RELATION MATRIX

\begin{tabular}{|c|c|c|c|c|c|c|c|}
\hline Factor & $\mathrm{F}_{1}$ & $\mathrm{~F}_{2}$ & $\mathrm{~F}_{3}$ & $\mathrm{~F}_{4}$ & $\mathrm{~F}_{5}$ & $\mathrm{~F}_{6}$ & $\mathrm{~F}_{7}$ \\
\hline $\mathrm{F}_{1}$ & 0.000 & 0.000 & 0.000 & 0.000 & 0.217 & 0.000 & 0.000 \\
\hline $\mathrm{F}_{2}$ & 0.175 & 0.000 & 0.000 & 0.226 & 0.156 & 0.234 & 0.209 \\
\hline $\mathrm{F}_{3}$ & 0.165 & 0.000 & 0.000 & 0.134 & 0.174 & 0.232 & 0.000 \\
\hline $\mathrm{F}_{4}$ & 0.134 & 0.000 & 0.000 & 0.000 & 0.143 & 0.223 & 0.000 \\
\hline $\mathrm{F}_{5}$ & 0.213 & 0.000 & 0.000 & 0.000 & 0.000 & 0.000 & 0.000 \\
\hline $\mathrm{F}_{6}$ & 0.215 & 0.000 & 0.000 & 0.000 & 0.244 & 0.000 & 0.000 \\
\hline $\mathrm{F}_{7}$ & 0.000 & 0.000 & 0.223 & 0.215 & 0.146 & 0.000 & 0.000 \\
\hline
\end{tabular}

\section{Calculate the Total Relation Matrix}

Once the normalized direct-relation matrix $\mathrm{M}$ is calculated, the total-relation matrix $\mathrm{T}$ can be acquired using the following equation, in which "I" is denoted as the identity matrix. Matrix T is shown in TABLE V.

$$
T=M(I-M)^{-1}
$$

TABLE V: THE TOTAL RELATION MATRIX

\begin{tabular}{|c|c|c|c|c|c|c|c|}
\hline Factor & $\mathrm{F}_{1}$ & $\mathrm{~F}_{2}$ & $\mathrm{~F}_{3}$ & $\mathrm{~F}_{4}$ & $\mathrm{~F}_{5}$ & $\mathrm{~F}_{6}$ & $\mathrm{~F}_{7}$ \\
\hline $\mathrm{F}_{1}$ & 0.048 & 0.000 & 0.000 & 0.000 & 0.227 & 0.000 & 0.000 \\
\hline $\mathrm{F}_{2}$ & 0.369 & 0.000 & 0.047 & 0.278 & 0.389 & 0.307 & 0.209 \\
\hline $\mathrm{F}_{3}$ & 0.308 & 0.000 & 0.000 & 0.135 & 0.324 & 0.262 & 0.000 \\
\hline $\mathrm{F}_{4}$ & 0.235 & 0.000 & 0.000 & 0.000 & 0.249 & 0.223 & 0.000 \\
\hline $\mathrm{F}_{5}$ & 0.223 & 0.000 & 0.000 & 0.000 & 0.048 & 0.000 & 0.000 \\
\hline $\mathrm{F}_{6}$ & 0.279 & 0.000 & 0.000 & 0.000 & 0.304 & 0.000 & 0.000 \\
\hline $\mathrm{F}_{7}$ & 0.152 & 0.000 & 0.223 & 0.245 & 0.279 & 0.106 & 0.000 \\
\hline
\end{tabular}




\section{Produce a Causal Diagram}

The sum of rows and the sum of columns are separately denoted as $\mathrm{D}$ and $\mathrm{R}$ within the total relation matrix through the following equations.

$$
\begin{gathered}
T=t_{i j} \quad i, j=1,2, \ldots, n \\
D=\sum_{j=1}^{n} t_{i j} \\
R=\sum_{i=1}^{n} t_{i j}
\end{gathered}
$$

Then, the horizontal axis vector $(\mathrm{D}+\mathrm{R})$ named "driving power" is made by adding D to R. Similarly, the vertical axis (D - R) named ' dependence"' is made by subtracting D from R. Generally, when (D - R) is positive, the criterion belongs to the driver group. Otherwise, if the (D - R) is negative, the criterion belongs to the dependent group. The causal diagram can be acquired by mapping the dataset of $(D+R, D-R)$.

Matrix $\mathrm{T}$ provides useful information on how one factor affects another. But it is necessary for a decision maker to set up a threshold value to filter out some negligible effects. Thus, only the effects greater than the threshold value would be chosen and shown in diagraph. In this study, the threshold value is set up by computing the average of the elements in matrix $\mathrm{T}$.

TABLE VI: THE AMOUNTS OF $(D+R)$ AND
\begin{tabular}{|c|c|c|}
\hline Factor & $(D+R)$ & $(D-R)$ \\
\hline $\mathrm{F}_{1}$ & 1.890 & -1.340 \\
\hline $\mathrm{F}_{2}$ & 1.597 & 1.597 \\
\hline $\mathrm{F}_{3}$ & 1.297 & 0.759 \\
\hline $\mathrm{F}_{4}$ & 1.364 & 0.049 \\
\hline $\mathrm{F}_{5}$ & 2.090 & -1.547 \\
\hline $\mathrm{F}_{6}$ & 1.481 & -0.314 \\
\hline $\mathrm{F}_{7}$ & 1.213 & 0.796 \\
\hline
\end{tabular}

The relationships between the factors are shown in the causal diagram (Fig. 2). This diagram indicates that how on factor affects on the other factors.

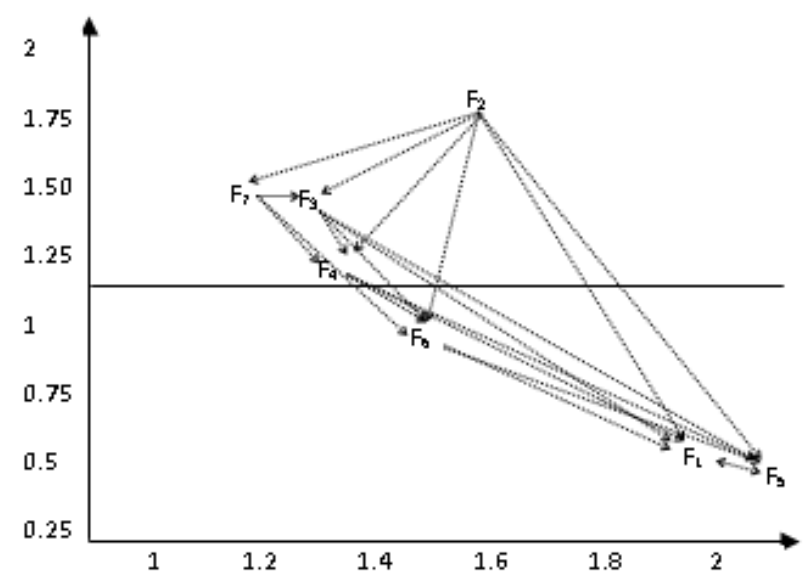

Fig. 2. The causal diagram.

\section{CONCLUSION}

An increasing number of Iranian SMEs attempt to implement BPR to achieve its benefits. In this paper we applied a DEMATEL methodology to better understand the CSFs. This paper identified 7 CSFs and developed a causal model of them, which indicates the inter-relationships between these CSFs. The identified CSFs also classified into two groups of driver and dependent factors. From the values of $(\mathrm{D}-\mathrm{R})$, it is observed that four factors namely "top management commitment", "IT infrastructure", "training" and "adequate financial resources" are driver, while the other CSFs are dependent. Therefore these four CSFs play a main role in BPR implementation. The finding of this paper can be used as guideline for managers to concentrate on the most influential factors. It is hoped that the findings of the study and the developed causal model offer insights to help managers effectively involve in BPR implementation projects. However, much more work of this type needs to help managers and organizations to make important decisions for adoption and implementation of BPR programs.

\section{REFERENCES}

[1] M. Hesson, H. Al-Ameed, and M. Samaka, "Business Process Reengineering in UAE Public Sector: A Town Planning Case Study," Business Process Management Journal, vol. 13 no. 3, pp. 348-378, 2007.

[2] M. Al-Mashari, Z. Irani, and M. Zairi, "Business Process Reengineering: A Survey of International Experience," Business Process Management Journal, vol. 7, no. 5, pp. 437- 455, 2001.

[3] M. Attaran, "Information Technology and Business-process Redesign," Business Process Management Journal, vol. 9, no. 4, pp. 440-458, 2003.

[4] M. E. Terziovski, P. Fitzpatrick, and P. O’Neill, "Successful Predictors of Business Process Reengineering (BPR) in Financial Services," International Journal of Production Economics, vol. 84, pp.35-50, 2003.

[5] N. Abdolvand, A. Albadvi, and Z. Ferdowsi, "Assessing Readiness for Business Process Reengineering," Business Process Management Journal, vol. 14, no. 4, pp. 497-511, 2008.

[6] G. Valiris and M. Glykas, "Business Analysis Metrics for Business Process Redesign,” Business Process Management Journal, vol. 10, no. 4, pp. 445-480, 2004.

[7] K. K. Chan and T. A. Spedding, "An Integrated Multidimensional Process Improvement Methodology for Manufacturing Systems," Computers and Industrial Engineering, vol. 44, pp. 673-93, 2003.

[8] K. Salimifard, M. A. Abbaszadeh, and A. Ghorbanpur, "Interpretive Structural Modeling of Critical Success Factors in Banking Process Re-engineering," International Review of Business Research Papers, vol. 6, no. 2, pp.95-103, 2010.

[9] M. Hammer, "Reengineering Work: Don't Automate, Obliterate," Harvard Business Review, pp. 104-112, 1990.

[10] M. Hammer, "Beyond Reengineering: How the Process-Centered Organization is Changing Our Work and Our Lives," HarperCollins, New York, NY. 1996.

[11] T. H. Davenport and J. E. Short, "The New Industrial Engineering: Information Technology and Business Process Redesign," Sloan Management Review, vol. 31, no. 4, pp. 11-27, 1990.

[12] M. Hammer and J. Champy, "Reengineering the Corporation," Harper Business, New York, NY. 1993.

[13] T. H. Davenport, "Need Radical Innovation and Continuous Improvement? Integrate Process Reengineering and TQM," Planning Review, vol. 22, no. 3, 1993.

[14] T. H. Davenport, "Process Innovation: Reengineering Work through Information Technology," Harvard Business School Press, Boston, MA. 1993

[15] J. Champy, "Reengineering Management: The Mandate for New Leadership," HarperCollins, New York, NY. 1995.

[16] R. Jain, A. Chandrasekaran, and A. Gunasekaran, "Benchmarking the Redesign of "Business Process Reengineering Curriculum - A Continuous Process Improvement (CPI)," Benchmarking: An International Journal, vol. 17, no. 1, pp. 77-94, 2010. 
[17] D. Paper and R. Chang, "The State of Business Process Reengineering: A Search for Success Factors," Total Quality Management \& Business Excellence, vol. 16, no. 1, pp.121-133, 2005.

[18] H. Harrington, "Business Process Improvement," McGraw-Hill, New York, 1991.

[19] M. M. Klein, "IEs Fill Facilitator Role in Benchmarking Operations to Improve Performance," Industrial Engineering, vol. 25, no. 9, pp. 4043, 1993.

[20] H. Johansson, P. McHugh, J. Pendlebury, and W. Wheeler, "Business Process Reengineering: Breakpoint Strategies for Market Dominance," Wiley, West Sussex, 1993.

[21] J. R. Dixon, P. Arnold, J. Heineke, J. S. Kim, and P. Mulligan, "Business Process Reengineering: Improving in New Strategic Directions," California Management Review, vol. 36, no. 4, pp. 93-108 1994.

[22] R. L. Manganelli, and M. M. Klein, "The Re-engineering Handbook: A Step-by-step Guide to Business Transformation," AMACOM, New York, 1994.

[23] C. D. Beugré, "Implementing Business Process Reengineering: The Role of Organizational Justice," Journal of Applied Behavioral Science, vol. 34, no. 3, pp. 347-360, 1998.

[24] A. Gunasekaran and B. Kobu , "Modelling and Analysis of Business Process Reengineering," International Journal of Production Research vol. 40, no. 11, pp. 2521-2546, 2002.

[25] C. Temponi, "Scalable Enterprise Systems: Quality Management Issues," International Journal of Production Economics, vol. 99, pp. 222-35, 2006.

[26] I. -L. Wu, "Understanding Senior Management's Behavior in Promoting the Strategic Role of IT in Process Reengineering: Use of the Theory of Reasoned Action," Information \& Management, vol. 41, 2003, pp. 1-11.

[27] Y. M, "How Does the Enterprise Implement Business Process Reengineering Management," 2010 International Conference on E-Business and E-Government.

[28] A. Lindsay, D. Downs, and K. Lunn, "Business Processes - Attempts to Find a Definition," Information and Software Technology, vol. 45, pp. 15-19, 2003.

[29] G. Hall, J. Rosenthal, and J. Wade, "How to Make Reengineering Really Work," Harvard Business Review, vol. 71, no. 6, pp. 119-131, 1993.

[30] M. Attaran, and G. G. Wood, "How to Succeed at Reengineering," Management Decision, vol. 37, no. 10, pp. 752-765, 1999.

[31] N. Shin and D. F. Jemella, "Business Process Reengineering and Performance Improvement," The Case of Chase Manhattan Bank, Business Process Management Journal, vol. 8 no. 4, pp. 351-63, 2002.

[32] T. Tonnessen, "Process Improvement and the Human Factor," Total Quality Management, vol. 11, no.4/5, pp. S773-8, 2002.

[33] J. R. Farmer, "Reengineering the Factory," Production and Inventory Management Journal, vol. 34, no. 1, pp. 38-42, 1993.

[34] H. L. Hales and B. J. Savoie, "Building a Foundation for Successful Business Process Reengineering," Industrial Engineering, vol. 26, no. 9, pp. 17-20, 1994.

[35] B. D. Bruyn and L. Gelders, "From TQM to BPR: Two Case Studies in Personnel Administration," International Journal of Production Economics, vol. 50, no. 2/3, pp. 169181,1997.

[36] C. Ranganathan and J. S. Dhaliwal, "A survey of Business Process Reengineering Practices in Singapore," Information \& Management, vol. 39, pp. 125-134, 2001.

[37] A. R. Dennis, T. A. Carte, and G. G. Kelly, "Breaking the Rules: Success and Failure in Groupware-supported Business Process Reengineering," Decision Support Systems, vol. 36, pp. 31-47, 2003.

[38] D. Holland and S. Kumar, "Getting Past the Obstacles to Successful Reengineering," Business Horizons, 1995, pp. 79-85.

[39] C. Chiplunkar, S. G. Deshmukh, and R. Chattopadhyay, "Application of Principles of Event Related Open Systems to Business Process Reengineering," Computers \& Industrial Engineering, vol. 45, 2003, pp. 347-374.

[40] M. O. Adigun and D.P. Biyela, "Modeling an Enterprise for Re-engineering: A Case Study," ACM International 2003 Annual Research Conference of the South African Institute of Computer Scientists and Information Technologists on Enablement through Technology, 2003, pp. 153-164.

[41] T. J. Crowe, P. M. Fong, and J. L. Zayas-Castro, "Quantative Risk Level Estimation of Business Process Reengineering Efforts," Business Process Management Journal, vol. 8,no. 5, pp. 490-511, 2002

[42] R. S. Maull, D. R. Tranfield, and W. Maull, "Factors Characterising the Maturity of BPR Programmes," International Journal of Operations and Production Management, vol. 23, no. 6, pp. 596-624, 2003.
[43] J. Motwani, R. Subramanian, and P. Gopalakrishna, "Critical Factors for Successful ERP Implementation: Exploratory Findings from Four Case Studies" Computers in Industry, vol. 56, pp. 529-544, 2005.

[44] H. A. Reijers and S. L. Mansar, "Best Practices in Business Process Redesign: An Overview and Qualitative Evaluation of Successful Redesign Heuristics," Omega, vol. 33, no. 4, pp. 283-306, 2005.

[45] S. L. Mansar, F. Marir, and H. A. Reijers, "Case-based Reasoning as a Technique for Knowledge Management in Business Process Redesign,' Electronic Journal on Knowledge Management, vol. 1, no. 2, pp. 113-124, 2003.

[46] H. Ahmad, A. Francis, and M. Zairi, "Business Process Reengineering: Critical Success Factors in Higher Education," Business Process Management Journal, vol. 13, no. 3, pp. 451-469, 2007.

[47] H. R. Ahadi, "An Examination of the Role of Organizational Enablers in Business Process Reengineering and the Impact of Information Technology," Information Resource Management Journal, vol. 17, no. 4, pp. 65-72.35-50, 2004.

[48] D. Grant, "A Wider View of Business Process Reengineering," Communications of the ACM, vol. 45, no. 2, pp. 84-92, 2002.

[49] T. Guimaraes, "Field Testing of the Proposed Predictors of BPR Success in Manufacturing Firms," Journal of Manufacturing Systems, vol. 18 , no. 1, pp. 53-65, 1999.

[50] M. Attaran, "Why Does Reengineering Fail? A Practical Guide for Successful Implementation," Journal of Management Development, vol. 19, no. 9, pp. 794-801, 2000.

[51] R. McAdam, "Radical Change: A Conceptual Model for Research Agendas," Leadership \& Organization Development Journal, vol. 24, no. 4, pp. 226-35, 2003.

[52] M. A. Abbaszadeh, M. Ebrahimi, and H. Fotouhi, "Developing a Causal Model of Critical Success Factors for Knowledge Management Implementation," International Conference on Education and Management Technology, Cairo, Egypt, 2010.

[53] J. Shieh, H. Wu, and K. Huang, "A DEMATEL Method in Identifying Key Success Factors of Hospital Service Quality," Knowledge-Based Systems, vol. 23, pp. 277-282, 2010.

[54] G. H. Jamali, M. Ebrahimi, and M. A. Abbaszadeh, "TQM Implementation: An Investigation of Critical Success Factors," International Conference on Education and Management Technology, Cairo, Egypt, 2010.

[55] W. J. Ho, C. Tsai, G. Tzeng, and S. Fang, "Combined DEMATEL Technique with a Novel MCDM Model for Exploring Portfolio Selection based on CAPM," Expert Systems with Applications, vol. 42, pp. 832-839, 2010.

[56] W. H. Tsai and W. C. Chou, "Selecting Management Systems for Sustainable Development in SMEs: A Novel Hybrid Model based on DEMATEL, ANP, and ZOGP," Expert Systems with Applications, vol. 36, pp. 1444-1458, 2009.

[57] W. W. Wu, "Choosing Knowledge Management Strategies by Using a Combined ANP and DEMATEL Approach," Expert Systems with Applications, vol. 35, pp. 828-835, 2008.

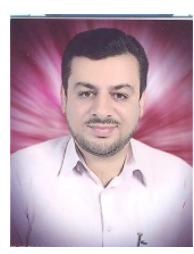

Gholamreza Jamali is an Assistant Professor, Bushehr, Iran. Dr Jamali holds a bachelor and a master's degree in Industrial Management from Shiraz University. He completed his $\mathrm{PhD}$ degree in production and operation management at Tehran University. His area of research interest include workforce scheduling, supply chain, project management, business process reengineering, quality management, enterprise resourse planning and knowledge management.

Dr Jamali has published many papers in national and international journals and conferences. He has worked as a consultant in many organizations.

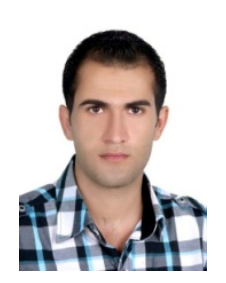

Mohammad Ali Abbaszadeh is a $\mathrm{PhD}$ student in Production and Operation Management at Tehran University, Kish International Campus, Kish, Iran. His bachelor's degree is in industrial management and he completed his Master of degree in industrial managment at Persian Gulf University, Bushehr, Iran, in 2009. His areas of research interest include workforce scheduling, business process reengineering, quality management, enterprise resourse planning and knowledge management. Mr Abbaszadeh has published several papers in national and international journals and conferences.

Before joining the $\mathrm{PhD}$ program he worked as a consultant for Iranian SMEs. 


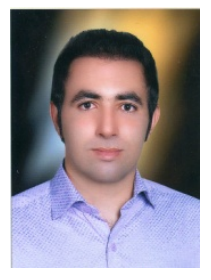

Mehran Ebrahinmi holds a Master's degree in Industrial Management from Persian Gulf University, Bushehr, Iran. His undergraduate degree was in Business Management from Iran. He has published several research papers in the national and international journals and conferences. His research interest is in the areas of workforce scheduling, quality management, business process management, service quality, and enterprise resource planning systems.

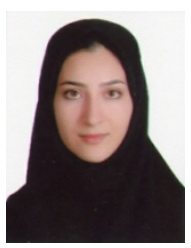

Tahereh Maleki holds a Master's degree in industrial management from Islamic Azad University, Tehran, Iran. Her undergraduate degree was in industrial Managemen from Persian Gulf University, Bushehr, Iran. She has published papers in the national and international conferences. Her research interest is in the areas of marketing, business process reengineering and knowledge management. 